\title{
A Solar System to reduce the Power Crisis in Bangladesh through Electric Vehicle Recharging Station
}

\author{
Sikder Sunbeam Islam ${ }^{1}$, Md. Jashim Uddin ${ }^{2}$ \\ I'Lecturer, Department of EEE, International Islamic University Chittagong, Bangladesh) \\ ${ }^{2}$ (Lecturer, Department of EEE, International Islamic University Chittagong, Bangladesh)
}

\begin{abstract}
Renewable energy resources can play an important role in a developing country like Bangladesh. In Bangladesh the electric vehicles powered by rechargeable batteries are becoming popular day by day. But it is a matter of great regret that a big amount of power is being used daily to recharge their batteries at the recharging stations. As Bangladesh faces acute power crisis this is a big challenge. This paper has proposed a $P V$ based recharging station for electric vehicles and made a detail analysis on it.
\end{abstract}

Keywords: Solar System, Recharging Station, Power System.

\section{Introduction}

An enormous amount of energy is extracted, distributed, converted and consumed daily in the present world. The energy demand in the whole world is increasing day by day. Today's global energy production is high, in fact 83\% [1]. At present the power demand in Bangladesh is about $6500 \mathrm{MW}$ which was $6000 \mathrm{MW}$ in the last year (2011) and the generation capacity is around 5000MW but peak demand is estimated to exceed 5,000 MW [2]. Moreover, our average growth demand is around 7\% which indicates that if we do not add $10 \%$ every year we going to face a big electricity crisis problem in the near future [13].

Monthly global solar insolation and daily average bright sunshine hour in Dhaka city are presented in Figure 1.1 and 1.2 respectively [3].

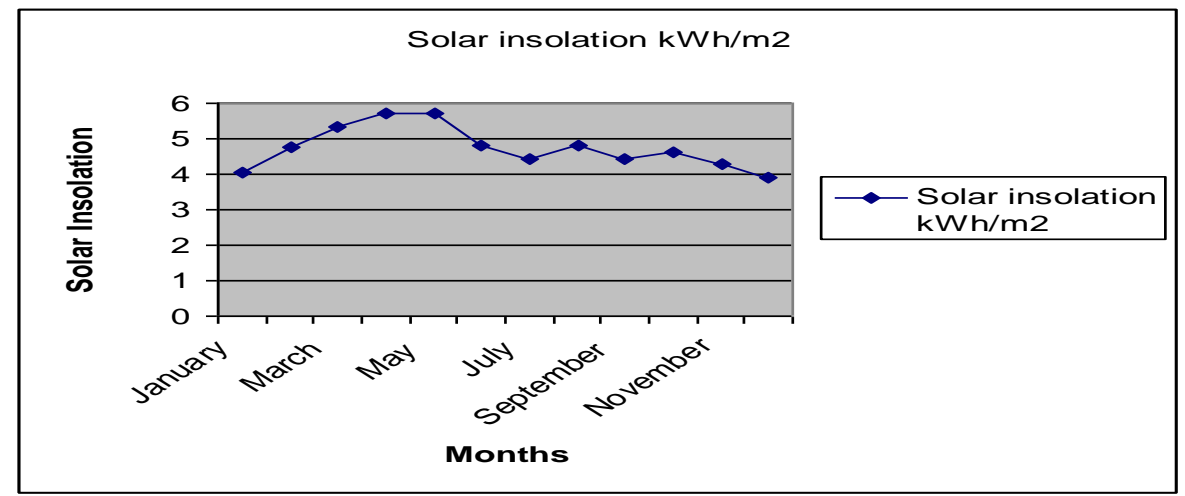

Figure1.1: Monthly solar insolation at Dhaka

From the Fig 1.1, it is found that the average solar insolation is 4.73 for Dhaka and from Fig 1.2, the daily average bright sunshine is 7.55 hours for Dhaka. The solar resource is abundant in Bangladesh as the tropic of cancer passes closely through the geographical centre of Bangladesh. So, the average Global Horizontal Irradiance is $625 \mathrm{~W} / \mathrm{m}^{2}$ [4].

Irradiance $=($ Average Insolation $) / \square \square$ Average daily bright sunshine hours $)$,

For our system we have to consider Solar insolation $=4.7 \mathrm{kWh} / \mathrm{m}^{2}$

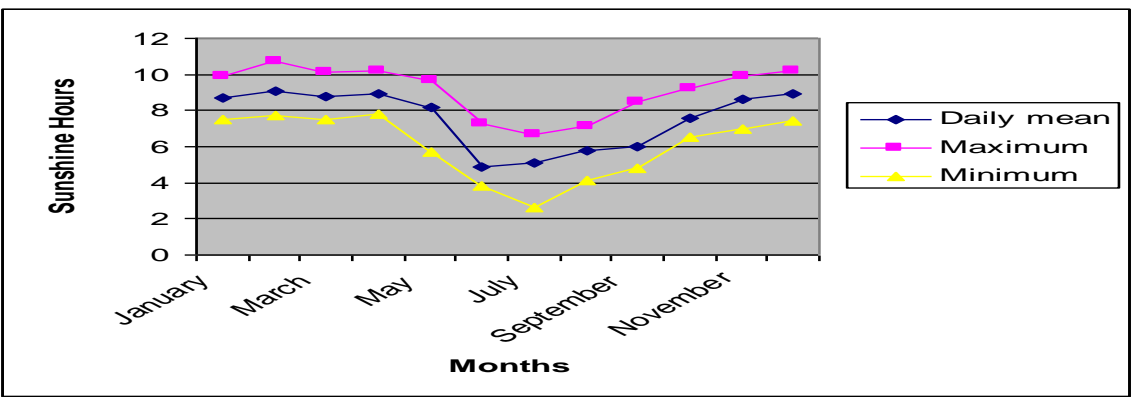

Figure 1.2: Daily average bright sunshine hours at Dhaka City 
Electric Vehicles also known as Easy Bikes [5] in Bangladesh are rechargeable battery based energy efficient and environment friendly popular vehicles. As it is rechargeable battery based there is needed a lot of power every day. As a result the power crisis is increased. But there is a lot of fuel recharging stations in Bangladesh where there is a great opportunity to implement solar based recharging station.

For designing and cost analysis data are collected from local and international markets and the electricity production's data is calculated manually with respect to Dhaka city.

\section{Electric Vehicle}

Electric vehicles (EVs) are propelled by an electric motor (or motors) which are powered by rechargeable battery packs [6]. Electric motors have several advantages over internal combustion engines (ICEs) [6]:

- It is 55\% more energy efficient than typical internal combustion engines (ICEs) based vehicles.

- It is more environment friendly than typical internal combustion engines (ICEs) based vehicles.

- It provides stronger acceleration and smooth operation than that of ICE based vehicles.

- It needs comparatively less Maintenance and it is easier.

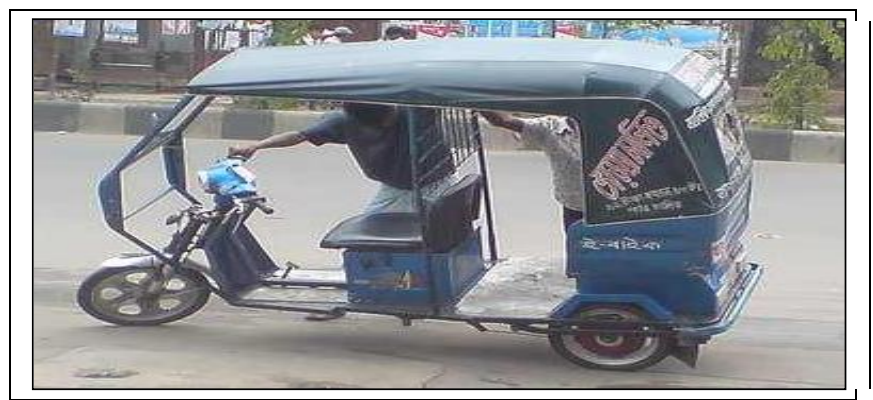

Figure 2.1 An electric vehicle in Dhaka City [5]

\subsection{Location}

\section{Design Of Pv System} East [7].

Dhaka is the capital of Bangladesh. Dhaka's geographical coordinates are $23^{\circ} 43^{\prime} 23^{\prime \prime}$ North, $90^{\circ} 24^{\prime} 31^{\prime \prime}$

\subsection{Module Accommodation on Roof Area}

The PV modules are accommodated on the roof of fuel filing stations. Generally the roof is plain as a result there is no problem to set up but for maximum efficiency the PV modules are tilted with an angle which depends on the location of the installation. The PV module is accommodated on roof area of the fuel filling station like Fig 3.1.

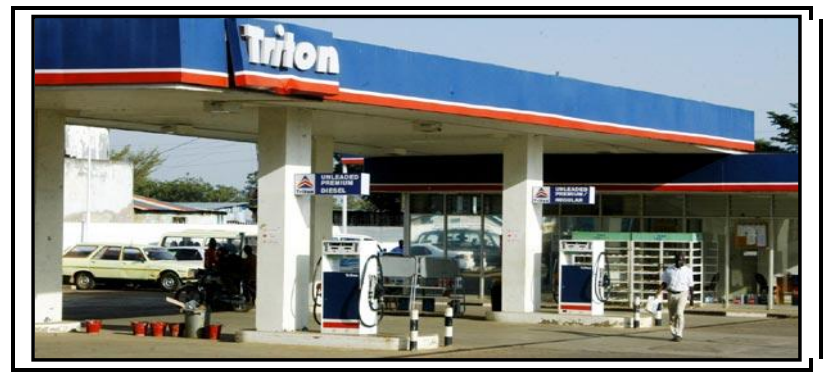

Figure 3.1: A general fuel filling station

For this system let us consider the length of the roof is around 80 feet and the breadth is around 40 feet. The layout is given in figure 3.2. The number of components is calculated with the help of this consideration. 


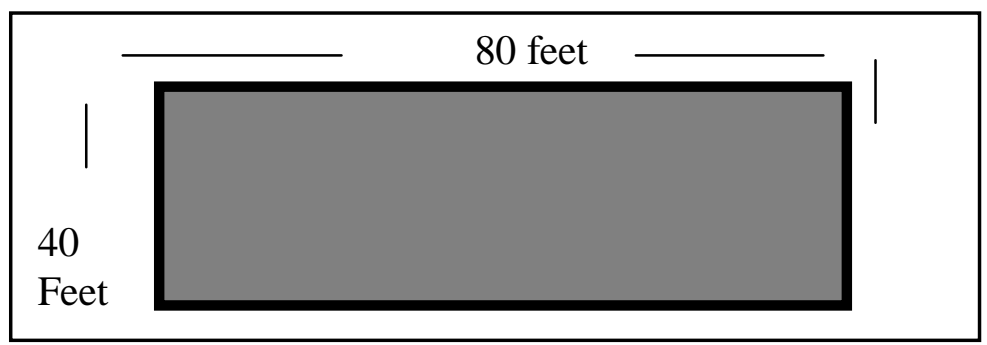

Figure 3.2: The considered layout

\subsection{System Design}

As a solar based system the system can be designed with some PV modules, Charge Controller boxes, control circuit etc in the system and the representation of block diagram is given in Figure 3.3.

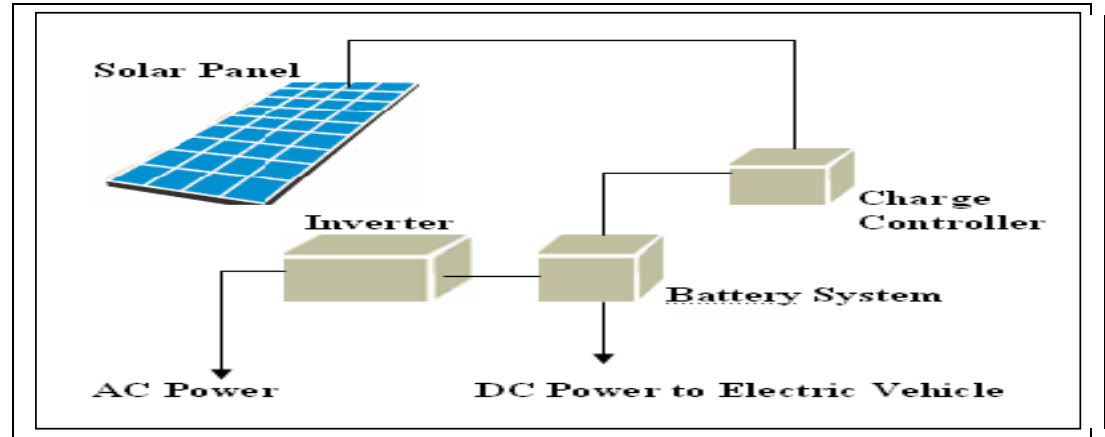

Figure 3.3: Total block diagram for the System

\subsection{Cost Analysis}

\subsubsection{Solar Energy}

Our estimated system capacity is $8 \mathrm{KW} /$ day and our daily average bright sunshine is 7.55 hours for Dhaka. So, total energy per day is $(8 \times 7.55)=60.4 \mathrm{KWh} /$ day. Considering overall efficiency $55 \%$ total input power $=8 / 0.55=14.55 \mathrm{KW}$. If we choose $230 \mathrm{~W}$ solar panel each, the number of solar panels will be $=(14.55 \times 1000) / 230$ $=63.24 \approx 63$.

\subsubsection{Battery Bank Calculation}

Suppose, the voltage rating of the battery for the battery bank $=12$ Volt.

Capacity of each battery $=120$ Amp-hour.

So, energy stored in each battery $=120 \times 12=1440=1.44 \mathrm{KWh}$

Maximum KWh needed/day (in December ) $=71.2 \mathrm{KWh}$; see Figure-5.1

The rest energy per day is needed to be stored $=(71.2-60.4) \mathrm{KWh}=10.8 \mathrm{KWh}$.

So, number of battery needed $=10.8 / 1.44=7.5 \approx 8$ batteries.

The different essential components with respective quantity and costs are given in Table 4.1.

Table 4.1: Cost components of our proposed system.

\begin{tabular}{|c|c|c|c|}
\hline Component & Description & $\overline{Q t y}$ & Cost in Taka \\
\hline PV module & $\begin{array}{c}\text { Sharp NU-U235F1 } \\
{[8]}\end{array}$ & 63 (Calculated) & $\begin{array}{c}63 * 46,000 \\
=28,98,000\end{array}$ \\
\hline Inverter & $\begin{array}{c}\text { 3000VA inverter } \\
{[10]}\end{array}$ & 7 (Calculated) & $\begin{array}{c}28,000 * 7= \\
1,96,000\end{array}$ \\
\hline $\begin{array}{l}\text { Charge } \\
\text { controller }\end{array}$ & Local market & 1 & 1,000 \\
\hline Wiring & Approximate & & 5,000 \\
\hline Battery & 12 Volt & 8 & $\begin{array}{l}10,000 * 8 \\
=80,000\end{array}$ \\
\hline $\begin{array}{l}\text { Control circuit, } \\
\text { installation, } \\
\text { maintenance and } \\
\text { others }\end{array}$ & Approximate & & 20,000 \\
\hline \multicolumn{3}{|l|}{ Total } & $32,00,000$ \\
\hline
\end{tabular}


\#80 taka=1 US dollar (appx)

\section{Daily And Monthly Electricity Generation}

In our proposed system the estimated capacity is around $\mathbf{8} \mathbf{~ K W}$. So to find out the daily energy generation we have to multiply this number to monthly average sunshine duration and the maximum $71.2 \mathrm{KWh} /$ day is found in December. Again for finding the monthly energy generation we have to multiply daily energy generation to number of days of each month respectively. The calculated data is shown in fig 5.1.

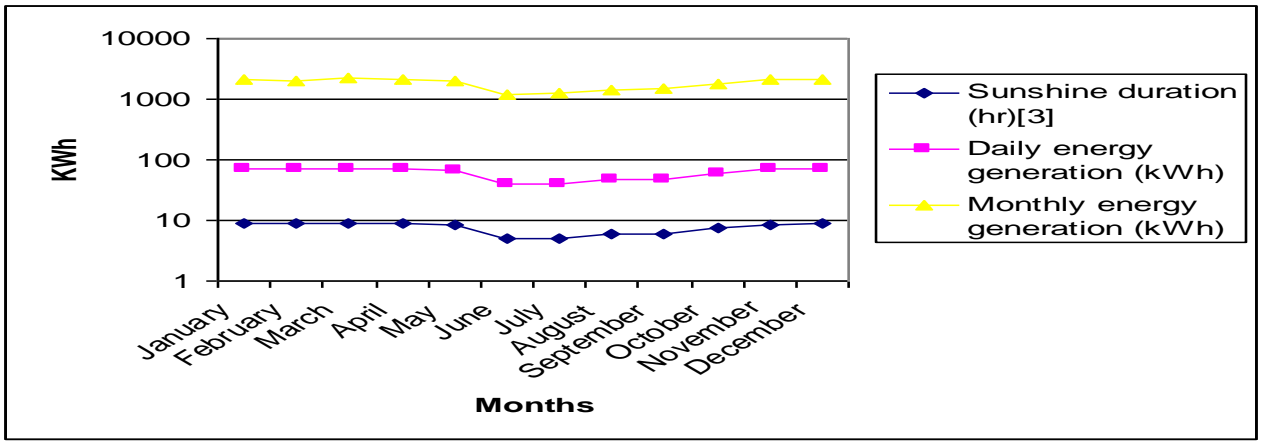

Figure 5.1: Daily and monthly average electricity generation in $\mathrm{kWh}$

\section{Monthly Income}

From the above fig 5.1 we can find the monthly energy generation. From monthly energy generation we can calculate the monthly income and the summation of monthly income is referred to annual income which helps us to find payback time of our proposed system. In figure the monthly incomes are shown which is calculated in different consideration and the considerations are per kilowatt hour equal to 6,8 and 10 respectively.

Table 6.1: monthly and yearly income of our proposed system

\begin{tabular}{|l|c|c|c|c|}
\hline Month & $\begin{array}{c}\text { Monthly } \\
\text { energy } \\
\text { generation } \\
(\mathbf{k W h})\end{array}$ & $\begin{array}{c}\text { Income in Taka } \\
(\mathbf{1} \mathbf{k W h = 6} \\
\mathbf{t a k a})\end{array}$ & $\begin{array}{c}\text { Income in Taka ( } \\
\mathbf{k W h}=\mathbf{8} \text { taka) }\end{array}$ & $\begin{array}{c}\text { Income in Taka ( 1 } \\
\mathbf{k W h}=\mathbf{1 0} \text { taka) }\end{array}$ \\
\hline January & $2,157.6$ & $12,945.6$ & $17,260.8$ & 21,576 \\
\hline February & $2,038.4$ & $12,230.4$ & 16307.2 & 20,384 \\
\hline March & $2,182.4$ & $13,094.4$ & 17459.2 & 21,824 \\
\hline April & 2,136 & 12,816 & 17088 & 21,360 \\
\hline May & $2,033.6$ & $12,201.6$ & 16268.8 & 20,336 \\
\hline June & 1,176 & 7,056 & 9408 & 11,760 \\
\hline July & $1,264.8$ & $7,588.8$ & 10118.4 & 12,648 \\
\hline August & $1,438.4$ & 8630.4 & 11507.2 & 14,384 \\
\hline September & 1,488 & 8,928 & 11904 & 18,880 \\
\hline October & 1,824 & 10,944 & 14592 & 21,328 \\
\hline November & $2,132.8$ & $12,796.8$ & 17062.4 & 21,360 \\
\hline December & 2,136 & 12,816 & 17088 & 220,080 \\
\hline \multicolumn{2}{|c|}{ Total (Yearly Incomes) } & 132,048 & 176,064 & \\
\hline \multicolumn{2}{|l}{} & & & \\
\hline
\end{tabular}

\section{Payback Time Analysis}

The payback time means that the number of years required for the improvement to pay for itself and for cost benefit analysis of our proposed system it is needed.

Simple payback time $=($ Cost of the system $) /($ Annual savings $)$, years

\section{Considering $1 \mathrm{kWh}=6$ taka:}

Cost of the system $=32,00,000$ taka

Annual income $=132,048$ taka

Payback time $($ year $)=($ Cost of the system $/$ Annual income $)=32,00,000 / 132,048=24.23$ year

Considering $1 \mathrm{kWh}=8$ taka:

Cost of the system $=32,00,000$ taka 
Annual income $=176,064$ taka

Payback time $($ year $)=($ Cost of the system $/$ Annual income $)=32,00,000 / 176,064=18.18$ year

Considering $1 \mathrm{kWh}=10$ taka:

Cost of the system $=32,00,000$ taka

Annual income $=220080$ taka

Payback time $($ year $)=($ Cost of the system $/$ Annual income $)=32,00,000 / 220,080=14.54$ year

\subsection{Opportunities and Benefits:}

\section{Opportunities, Benefits And Challenges}

The opportunities and benefits are given below:

1. The existing fuel stations can be used. No other site is needed to be selected. 2. The payback time is estimated and lesser than other system. 3. No extra labour cost and maintenance cost is needed. 4. Extra power can be used for the recharging station itself 5. This system becomes one of the factors to increase the income of the owners of fuel filling stations. 6. Proper utilization of solar energy. 7. Dependence on fossil fuels such as Diesel, Petrol and Gas etc is decreased. 8. It is a pollution free process.

\subsection{Challenges and Limitations:}

The challenges and limitations are given below:

1. Initial cost is high for the owner of the fuel filling stations. 2. The design must be perfect. 3. Lack of knowledge about proper maintenance of Solar based technologies. 4. During night and insufficient solar radiation the system is not work properly. 5. For fully recharging the battery pack can take 4 to 8 hours. Even a "quick charge" to $80 \%$ capacity can take 30 min [6].

VIII. Conclusion

Although the Electric vehicle has some limitations, its environment friendly nature has made it popular to all over the world. So, it is clear that our proposed system could be an effective one due to its necessity in the power crisis context. Though our proposed system is designed for Dhaka city and costs are calculated with respect to Dhaka city, this system is implemented anywhere in Bangladesh. And it is also said that this proposed system is economically and geographically feasible to Bangladesh.

\section{References}

[1] International Energy Agency: Share of total primary energy supply in 2003. Technical report, 2003.

[2] Press release of The World Bank on October 30, 2008

[3] REEI Available: http://www.reein.org/solar/resource/index.htm.

[4] Final report of Solar and Wind Energy Resource Assessment (SWERA), Renewable Energy Research Centre, Dhaka, Bangladesh, February 2007

[5] Available: http://biz.bdnews24.com/details.php?id=194924\&cid=4

[6] US Department of Energy Available: http://www.fueleconomy.gov/feg/evtech.shtml

[7] Available at: http://www.maplandia.com/bangladesh/dhaka-div/dhaka-zila/dhaka/ dated:

[8] Sharp NU-U235F1 datasheet; Sharp Electronics Corporation, CA. Available at: www.mrsolar.com/pdf/sharp/Sharp235U1F.pdf

[9] Midnite Solar MNPV3 datasheet,; Midnight Solar, USA. Available at: www.midnitesolar.com/pdfs/frontBack03.pdf

[10] Solarpac company Ltd. Data has been collected from local markets

[11] Bangladesh Road Transport Authority's news. Available: www.brta.gov.bd/

[12] Solar energy - Fundamentals and Application, By J. Gand and J. Prokash. Khanna Publications.p-134.

[13] HAQUE N.M. Ziaul; Electricity problem of Bangladesh; Wheel Buisness Magazine, Vol. 2 , Issue 1, January-March 2012. 